University of Nebraska - Lincoln

DigitalCommons@University of Nebraska - Lincoln

Faculty Publications in Food Science and Technology

Food Science and Technology Department

$2-2008$

\title{
Modeling Residence Time Distribution in a Twin-Screw Extruder as a Series of Ideal Steady-State Flow Reactors
}

\author{
Ajay Kumar \\ University of Nebraska-Lincoln, akumar2@unl.edu \\ Girish M. Ganjyal \\ University of Nebraska-Lincoln, gganjyal2@unl.edu \\ David D. Jones \\ University of Nebraska-Lincoln, david.jones@unl.edu \\ Milford Hanna \\ University of Nebraska-Lincoln, mhanna1@unl.edu
}

Follow this and additional works at: https://digitalcommons.unl.edu/foodsciefacpub

Part of the Food Science Commons

Kumar, Ajay; Ganjyal, Girish M.; Jones, David D.; and Hanna, Milford, "Modeling Residence Time Distribution in a Twin-Screw Extruder as a Series of Ideal Steady-State Flow Reactors" (2008). Faculty Publications in Food Science and Technology. 44.

https://digitalcommons.unl.edu/foodsciefacpub/44

This Article is brought to you for free and open access by the Food Science and Technology Department at DigitalCommons@University of Nebraska - Lincoln. It has been accepted for inclusion in Faculty Publications in Food Science and Technology by an authorized administrator of DigitalCommons@University of Nebraska - Lincoln. 
Published in Journal of Food Engineering 84:3 (February 2008), pp. 441-448; doi: 10. 1016/j. jfoodeng. 2007. 06. 017

Published by Elsevier Ltd. Used by permission. http://www.sciencedirect.com/science/journal/02608774

Submitted May 15, 2006; revised June 12, 2007; accepted June 16, 2007; published online July 12, 2007.

\title{
Modeling residence time distribution in a twin-screw extruder as a series of ideal steady-state flow reactors
}

\author{
Ajay Kumar, Girish M. Ganjyal, David D. Jones, and Milford A. Hanna \\ University of Nebraska-Lincoln, Industrial Agricultural Products Center, 211 L.W. Chase Hall, Lincoln, NE 68583-0730, USA \\ Corresponding author - M. A. Hanna, tel 402 472-1634, fax 402 472-6338, email mhanna1@unl.edu
}

\begin{abstract}
Knowledge about and control of residence time distribution (RTD) is critical for determining optimal conditions in an extrusion process. In this paper, previously proposed models for RTD have been summarized and compared with the experimental data. The best-fit model was found to be a plug flow in series with a finite number of constantly stirred tank reactors having dead volume fractions. Parameters of the best-fit model were predicted from input variables (moisture content, screw speed, nozzle diameter and barrel temperature). Predicted RTD from the input variables had a $r^{2}>0.96$. Experiments were conducted using a full factorial design with moisture contents of 16, 20, 24 and 28\% (wb); screw speeds of 80, 120 and $160 \mathrm{rpm}$; nozzle diameters of 3,4 and $5 \mathrm{~mm}$; and barrel temperatures of 120 and $140{ }^{\circ} \mathrm{C}$. Each experiment was replicated twice. It was found that, within the range of conditions studied, moisture content, screw speed, barrel temperature and nozzle diameter had significant effects on RTD.
\end{abstract}

Keywords: extrusion, modeling, constantly stirred tank reactors, residence time distribution

\section{Introduction}

The extrusion processes of interest herein are high temperature-high pressure-short time processes. To obtain and maintain desired product quality, it is necessary to process the feed material for an optimum time that is specific and controllable. Residence time distribution (RTD) is the parameter that depicts the time. In cases of scaling-up and transferring processes to different extruder geometries, most of the time, RTD is useful for comparison since it is measured easily and is a result of mass flow patterns (Jager, Van Zuilichem, \& Stolp, 1991).

Numerous attempts have been made to model and predict RTD under various operating conditions. Bigg and Middleman (1974) developed a mathematical model for a two-dimensional flow field in an extruder under the assumption that the melt material was a power-law fluid. They used the model to determine RTD during the process. Though these models were based fundamentally on fluid flow dynamics, a large number of fac- tors (e.g., screw and die designs and properties of the feed materials), the dynamic properties of the material and the assumptions involved made the model complex and results deviated from the experimental data.

There is another approach, namely conceptual flow modeling, in which the extrusion process is modeled as a series of ideal tank reactors. These models were derived basically for chemical reactors. Levenspiel (1972) and Wolf and Resnick (1963) described different types of single and multistage models and their applications. Levich, Markin, and Chismadzhev (1967) developed a model for hydrodynamic mixing assuming an infinite series of continuously stirred tank reactors (CSTRs). Davidson, Paton, Diosady, and Spratt (1983) compared these proposed conceptual models to predict RTD in the single-screw extruder. Experimental RTDs were explained well with the models. In this paper, a model of plug flow with a finite number of CSTRs having dead volume fractions in series is referred to as a "complete model." Yeh and Jaw (1999) proposed a "simplified model" assuming plug flow in series with one CSTR 


$\begin{array}{ll}\text { Nomenclature } \\ C(t) & \begin{array}{l}\text { concentration of tracer as a function of time } \\ \text { concentration of tracer at } i \text { th time interval } \\ \text { dead volume fraction }\end{array} \\ d & \text { concentration at exit as a function of time }(\mathrm{t}) \\ E(t) & \text { dimensionless plot of } E(t) \\ E(\theta) & \text { cumulative concentration at exit as a function of } \\ F(t) & \text { time }(\mathrm{t}) \\ F(\theta) & \text { dimensionless plot of } F(t) \\ n & \text { number of CSTRs } \\ p & \text { fraction of plug flow } \\ \text { sse } & \text { sum of squares of error }\end{array}$

with a dead volume fraction. They found that the simplified model and complete model represented the RTD better than other general conceptual models. However, the simplified model did not represent the initial portion of the distribution well. The complete model represents the simplified model when there is only one CSTR. Since, the complete model is the most generalized model among these models, estimating the parameters of the complete model from experimental residence time data would be more informative. There have been no reports on estimating and analyzing the parameters of the complete model based on the experimental data and comparing the validity of all proposed models. This was one objective of research reported herein.

Since, RTD develops as a result of flow and mixing patterns, it is highly dependent on the process variables. Several researchers studied the effects of process variables on RTD. Increasing screw speed shifted the RTD to the left with respect to the time axis and shortened the mean residence time (Altomare \& Ghossi, 1986). Gogoi and Yam (1994) developed an empirical exponential equation to relate mean residence time with screw speed in a twin-screw extruder. They also found that the spread of the RTD was minimally affected by the screw speed and barrel temperature had little effect on the residence time. However, there are some conflicting results in the literature on the effects of process variables on RTD. Ziegler and Aguilar (2003) found that the mean residence time was affected more linearly (with negative constant) than exponentially with screw speed. Wolf and White (1976) found no significant effect of screw speed on RTD and an increase in mixing was observed with an increase in the temperature in a plasticating screw extruder. Altomare and Ghossi (1986) observed that lower barrel temperature resulted in shorter mean residence times. They also found that moisture contents (10-28\%) had very little effect, when screws with conveying elements were used in a twin-screw extruder. During singlescrew extrusion of rice flour at barrel temperatures of $60-80{ }^{\circ} \mathrm{C}$ and moisture content of $35 \%(\mathrm{wb})$, Chuang and Yeh (2004) found that mean residence times were

\begin{tabular}{|c|c|}
\hline$\Delta t$ & time interval \\
\hline $\bar{t}$ & mean residence time (mrt) \\
\hline$t_{\min }$ & $\begin{array}{l}\text { time when color starts appearing in the } \\
\text { extrudate }\end{array}$ \\
\hline$\Delta t_{i}$ & $\begin{array}{l}\text { ith time interval } \\
\text { dimensionless time }\end{array}$ \\
\hline
\end{tabular}

$\begin{array}{ll}\text { Abbreviations } \\ \text { CSTR } & \text { continuously stirred tank reactor } \\ \text { MRT } & \text { mean residence time } \\ \text { PFR } & \text { plug flow reactor } \\ \text { RTD } & \text { residence time distribution }\end{array}$

much longer than for general food extrusion. RTD also was dependent on screw profile and die diameter.

Here, the effects of a wide range of conditions, i.e. moisture content, screw speed, nozzle diameters and barrel temperature, on RTD were analyzed in a twinscrew extrusion. The analysis was made based on effects of above process variables on the parameters of the complete model.

Ganjyal and Hanna (2002) reviewed the various aspects of RTD in the extrusion process and prospects of using neural network (NN) to model. Ganjyal, Hanna, and Jones (2003) predicted physical properties of waxy cross-linked starches using a NN model. Though NN models are good for complex systems, given the experimental data for specific conditions, the model became very specific for those conditions and extrapolation was not satisfactory. With an aim to see effectiveness of NN for prediction in this case, the performances of a simple NN model (fully connected three layers with back propagation method) and a statistical quadratic model were compared.

The overall objectives of this study were to estimate the parameters of the most-general complete model from the experimental data, compare the proposed conceptual models, and analyze and predict the effects of input variables (moisture content, screw speed, nozzle diameter and barrel temperature) on the model parameters.

\section{Theory}

$E(t)$ and $F(t)$ curves are usually used to analyze RTD. An $E(t)$ curve represents the variation in the concentration of tracer at extruder nozzle exit with time. The $F(t)$ curve represents the cumulative quantity of tracer at the exit with time.

Mathematically,

$$
\begin{aligned}
& E(t)=\frac{C(t)}{\int_{0}^{\infty} C(t) \mathrm{d} t}=\frac{C_{i}}{\sum_{0}^{\infty} C_{i} \Delta t_{i}} \\
& F(t)=\int_{0}^{t} E(t) \mathrm{d} t=\frac{\sum_{0}^{t} C_{i} \Delta t_{i}}{\sum_{0}^{\infty} C_{i} \Delta t_{i}}
\end{aligned}
$$


The following equation was developed for a complete model (plug flow with finite number of CSTRs with dead volume in series), after modifying the tank-in-series model (Levenspiel, 1972) to include plug flow and dead fractions

$$
E(\theta)=\frac{b[b(\theta-p)]^{n-1}}{(n-1) !} \exp [-b(\theta-p)]
$$

where

$$
b=\frac{n}{(1-p)(1-d)}
$$

Hence, the four parameters that fully represent this model are $\bar{t}, p, n$ and $d$. Other proposed models were described and compared by Davidson et al. (1983).

Mean residence time $(\bar{t})$ and fraction of plug flow $(p)$ were calculated as

$$
\begin{aligned}
& \bar{t}=\int_{0}^{\infty} t E(t) \mathrm{d} t=\frac{\sum t_{i} C_{i} \Delta t_{i}}{\sum C_{i} \Delta t_{i}} \\
& p=\frac{t_{\min }}{\bar{t}}
\end{aligned}
$$

A dimensionless parameter, normalized time $(\theta)$, was used to compare the RTD curves

$$
\theta=\frac{t}{\bar{t}}
$$

Thus, the dimensionless plots of $E(t)$ and $F(t)$ became

$$
\begin{aligned}
& E(\theta)=\frac{E(t)}{\bar{t}} \\
& F(\theta)=F(t)
\end{aligned}
$$

Abdelrahim et al. (1993), Altomare and Ghossi (1986), and Yeh and Jaw (1999) and others have used similar mathematical functions (Equations (1), (2), (5)-(9)) to represent the RTD for different food processing applications. However, Equations (3) and (4) were developed by simplifying the model presented by Levenspiel (1972) for this application.

\section{Materials and methods}

\subsection{Samples}

Starch, with 25\% amylose content (Melogel, National Starch and Chemical Co., Bridgewater, NJ, USA), was used as the feed material. Moisture content of the starch was adjusted from $16 \%$ to $28 \%(\mathrm{wb})$ by adding predetermined amounts of distilled water and mixing in a Hobart mixer (Model C-100, Hobart Corp., Troy, OH). Moisture contents of the samples were measured with a Metter Toledo HG53 Moisture Analyzer (Mettler Toledo Laboratory and Weighing Technologies, Greifensee, Switzerland). The wetted samples were poured into bottles and held for $12 \mathrm{~h}$ to equilibrate.

\subsection{Extrusion}

Experiments were carried out using a co-rotating, intermeshing, twin-screw extruder (Model CSTE-V, C.W.
Brabender, Inc., Hackensack, NJ) having conical screws with diameters decreasing from 43 to $28 \mathrm{~mm}$ along a length of $365 \mathrm{~mm}$ from feed end to exit end. Rotational speeds were varied from 80 to $160 \mathrm{rpm}$. The extruder was controlled by an Intelli-Torque Plasti-Corder (Type FE 2000, C.W. Brabender, Inc., S. Hackensack, NJ).

\subsection{Determination of RTD}

A pulse stimulus response technique was used to obtain the RTD. Tracer was prepared by mixing $0.05 \mathrm{mg}$ of erythrosin (red) dye (erythrosin B sodium salt, SigmaAldrich, St Louis, MO, USA) with $5 \mathrm{~g}$ of starch (similar to the method used by Altomare \& Ghossi, 1986). The extrudate samples were collected every $10 \mathrm{~s}$ from the time tracer was added and the change in concentration was determined by color measurements ( $a^{*}$ value of $L^{*} a^{*} b^{*}$ color space coordinates). Extrudates were ground in a micro-mill (Pequannock, NJ) and color measurements of the ground extrudates were taken using a Chroma meter (Model CR-300, Minolta, Japan). Experimental data were checked to eliminate large variations in the replicates. The experiments with large variation between their replicates were performed again using an improved color measurement method as described by Kumar, Ganjyal, Jones, and Hanna (2006). There were no differences in color measurements obtained by the two methods.

\subsection{Experimental design}

A full factorial design $(4 \times 3 \times 3 \times 2)$ of four starch moisture contents $(16,20,24$ and $28 \% \mathrm{wb})$, three screw speeds $(80,120$ and $160 \mathrm{rpm})$, three nozzle diameters $(3,4$ and $5 \mathrm{~mm})$ and two barrel temperatures (120 and $140^{\circ} \mathrm{C}$ ) was used. Each experiment was replicated twice with a total of 144 experiments. The parameter-values of RTD were averages of the replications.

\subsection{Analysis}

Two parameters of the complete model, $\bar{t}$ and $p$, were estimated from the RTD data using Equations (5) and (6). The other parameters, $d$ and $n$, were estimated based on least sum of squares of error (sse) since these two parameters could not be directly calculated from the experimental data using equations. The $d$ and $n$ values varied within the ranges of $0.0-0.1$ and $0-20$, respectively, and sse were obtained by comparing experimental data with the predicted data of complete model. The programming for above procedure was done using MATLAB 7.0 (The Mathworks Inc., Natick, MA, USA). Statistical analyses and development of quadratic models for prediction were done using SAS 8.2 (SAS Institute Inc., Cary, NC, USA). Proc Mixed was used to analyze the effects of input variables on parameters of the model and proc RSREG and proc REG were used to get the quadratic regression equations. Commercial soft- 
ware Neuroshell 2 (Release 4.0, Ward Systems Groups, Inc., Frederick, MD, USA) was used to build the neural network model for prediction of the parameters. The method used was fully connected three layers with back propagation (Bharath \& Dorsen, 1994). The total data set consisting of inputs and outputs for each set, were divided randomly into training, checking and testing sets, with $60 \%$ as training, $10 \%$ as checking and $30 \%$ as testing data sets. The performance of NN model was measured by the prediction capabilities when testing sets of data were subjected to the trained model. The $r$-squared and root mean squared errors (RMSE) were obtained for evaluating the model.

\section{Results and discussion}

\subsection{Comparison of models}

The complete model is the most general model among all proposed models described in detail by Davidson et al. (1983). The model represents the WolfResnich model when the plug flow fraction $(p)$ is zero,

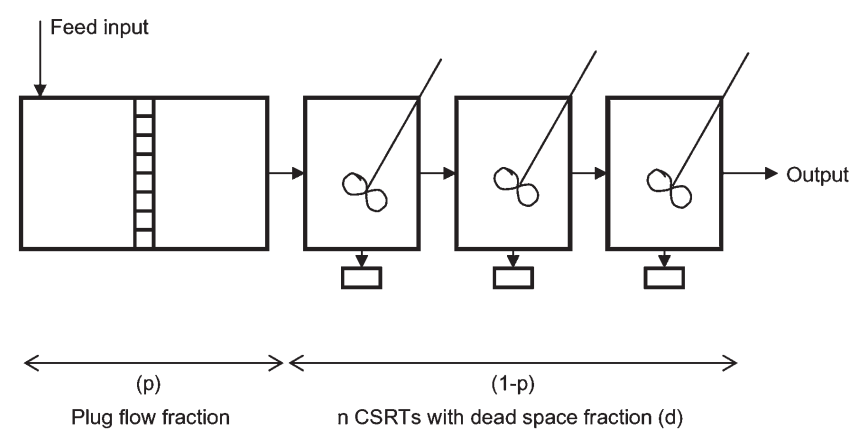

Figure 1. Schematic diagram of plug flow in series with continuouslystirred tank reactors having dead volume fractions. the Levich model when $n$ is very large and dead volume fraction $(d)$ is zero, and the simplified model when the value of $n$ is one. So, for comparison between the models, the four parameters of the "complete model" were estimated based upon the experimental RTD data (see Figure 1).

\subsection{Estimation of model parameter}

The first objective of this research was to estimate the model parameters from known experimental RTD at each extrusion condition, which was a curve-fitting problem.

Complete model parameters, $\bar{t}$ and $p$ were calculated directly from the experimental RTD using Equations (5) and (6). Parameters, $d$ and $n$ were estimated from least obtained sse. A typical plot (Figure 2) shows that the sse was dependent primarily on the $n$ value and not influenced by the value of $d$. The estimated parameters for all conditions are shown in Table 1 . For most conditions, $n$ was found to be either 2 or 3 , which may imply that 2 or 3 CSTRs in the model were adequate, and optimal for the model. The simplified model proposed by Yeh and Jaw (1999) contained only one CSTR. Figure 3 shows that though the simplified model was able to describe the tail portion of the curve, the initial portion did not fit with the experimental RTD curve. With a small modification of the simplified model, the complete model with 2 or 3 CSTRs, improved the predicted curve significantly. This also implies that the other proposed model (Levich model with infinite CSTR) was not suitable within the range of our experimental conditions.

\subsection{Effects of the process conditions on the model parameters}

Generally, $\bar{t}$ is the most common parameter of concern and is indicative of the average transient time of

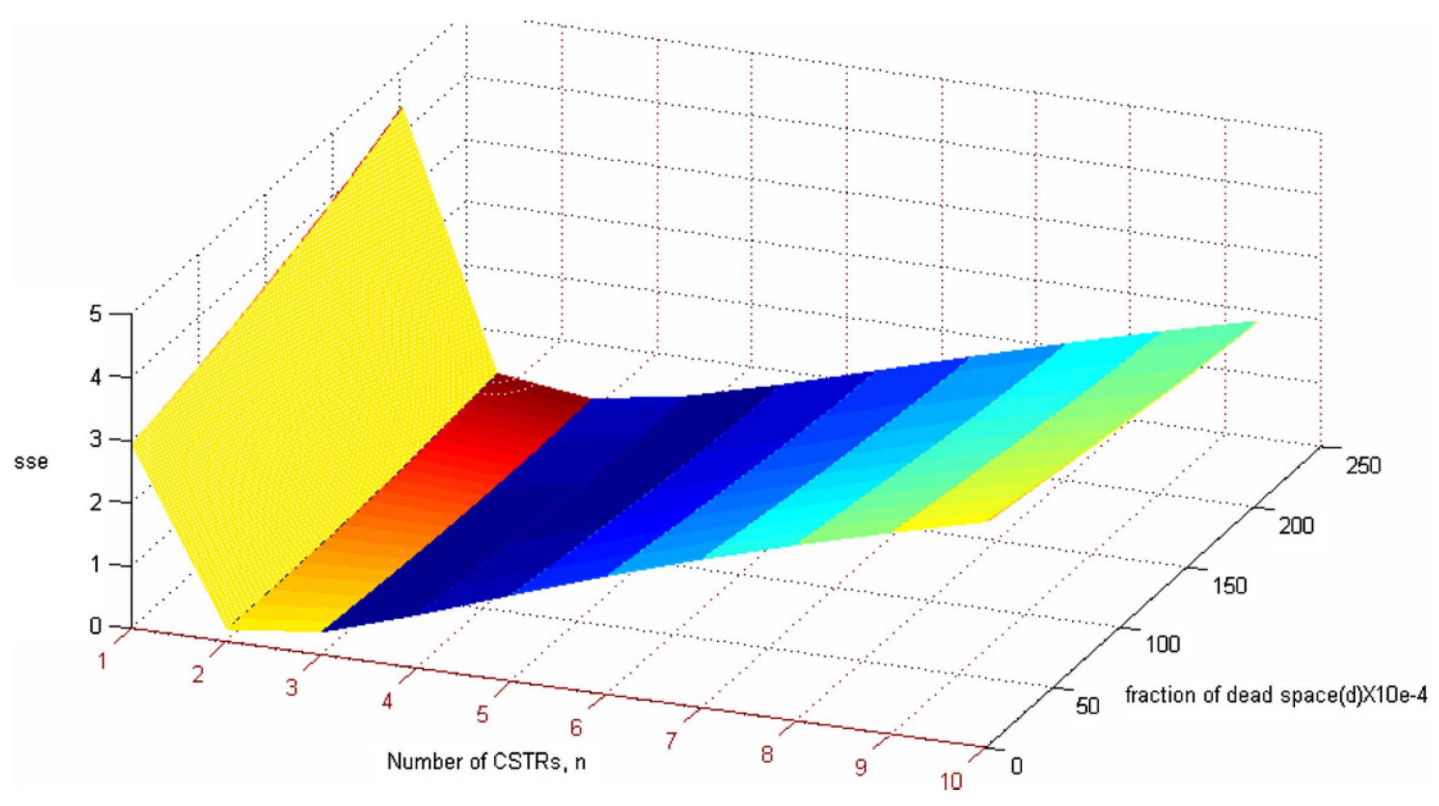

Figure 2. Sum of squares of error (sse) as a function of number of CSTR $(n)$ and fraction of dead volume $(d)$. 
Table 1. Estimated parameters of complete model for all experiments (average of replicates)

\begin{tabular}{|c|c|c|c|c|c|c|c|}
\hline $\begin{array}{l}\text { Moisture content } \\
(\%, \mathrm{wb})\end{array}$ & $\begin{array}{l}\text { Temperature } \\
\left({ }^{\circ} \mathrm{C}\right)\end{array}$ & $\begin{array}{l}\text { Screw speed } \\
(\mathrm{rpm})\end{array}$ & $\begin{array}{l}\text { Nozzle } \\
\text { diameter }(\mathrm{mm})\end{array}$ & $\begin{array}{l}\text { Mean residence } \\
\text { time, } t(\mathrm{~s})\end{array}$ & $\begin{array}{l}\text { Plug flow } \\
\text { fraction, } p\end{array}$ & $\begin{array}{l}\text { Dead volume } \\
\text { fraction, } d\end{array}$ & $\begin{array}{l}\text { Number of } \\
\text { CSTRs, } n\end{array}$ \\
\hline 16 & 120 & 80 & 3 & 77.1 & 0.32 & 0.097 & 2 \\
\hline 16 & 120 & 120 & 3 & 68.65 & 0.36 & 0.079 & 3 \\
\hline 16 & 120 & 80 & 4 & 75.99 & 0.32 & 0.132 & 2 \\
\hline 16 & 120 & 120 & 4 & 53.58 & 0.23 & 0.09 & 2 \\
\hline 16 & 120 & 160 & 4 & 37.76 & 0.13 & 0.2 & 3.5 \\
\hline 16 & 120 & 160 & 5 & 45.54 & 0.18 & 0.161 & 3 \\
\hline 16 & 140 & 80 & 3 & 115.67 & 0.41 & 0.013 & 3 \\
\hline 16 & 140 & 120 & 3 & 91.06 & 0.23 & 0.019 & 4 \\
\hline 16 & 140 & 160 & 3 & 70.73 & 0.35 & 0.021 & 2.5 \\
\hline 16 & 140 & 80 & 4 & 64.44 & 0.44 & 0.027 & 2 \\
\hline 16 & 140 & 120 & 4 & 49.49 & 0.3 & 0.046 & 2.5 \\
\hline 20 & 120 & 80 & 3 & 56.34 & 0.25 & 0.019 & 2 \\
\hline 20 & 120 & 120 & 3 & 92.9 & 0.26 & 0 & 2 \\
\hline 20 & 120 & 160 & 3 & 124 & 0.33 & 0 & 2 \\
\hline 20 & 120 & 80 & 4 & 55.55 & 0.27 & 0.088 & 2.5 \\
\hline 20 & 120 & 120 & 4 & 66.98 & 0.28 & 0.042 & 2 \\
\hline 20 & 120 & 160 & 4 & 112.02 & 0.29 & 0.063 & 2 \\
\hline 20 & 120 & 80 & 5 & 67.96 & 0.27 & 0.018 & 2 \\
\hline 20 & 120 & 120 & 5 & 64.34 & 0.23 & 0.064 & 2 \\
\hline 20 & 120 & 160 & 5 & 90.25 & 0.28 & 0 & 2 \\
\hline 20 & 140 & 80 & 3 & 93.72 & 0.32 & 0.026 & 2.5 \\
\hline 20 & 140 & 120 & 3 & 77.29 & 0.33 & 0.062 & 3 \\
\hline 20 & 140 & 160 & 3 & 51.66 & 0.34 & 0.067 & 2.5 \\
\hline 24 & 120 & 160 & 3 & 78.71 & 0.3 & 0.035 & 2.5 \\
\hline 24 & 120 & 80 & 4 & 86.94 & 0.37 & 0 & 2 \\
\hline 24 & 120 & 120 & 4 & 70.84 & 0.26 & 0.03 & 2 \\
\hline 24 & 120 & 160 & 4 & 51.93 & 0.29 & 0.104 & 3 \\
\hline 24 & 120 & 80 & 5 & 82.34 & 0.3 & 0 & 2 \\
\hline 24 & 120 & 120 & 5 & 58.98 & 0.39 & 0 & 2 \\
\hline 24 & 120 & 160 & 5 & 56.05 & 0.25 & 0.041 & 2.5 \\
\hline 24 & 140 & 80 & 3 & 81.53 & 0.29 & 0 & 2 \\
\hline 24 & 140 & 120 & 3 & 83.22 & 0.3 & 0.019 & 2 \\
\hline 24 & 140 & 160 & 3 & 98.49 & 0.3 & 0 & 2 \\
\hline 24 & 140 & 80 & 4 & 94.82 & 0.26 & 0.009 & 2 \\
\hline 24 & 140 & 120 & 4 & 71.92 & 0.26 & 0.073 & 2 \\
\hline 24 & 140 & 160 & 4 & 59.74 & 0.25 & 0.084 & 3 \\
\hline 24 & 140 & 80 & 5 & 85.3 & 0.29 & 0.045 & 2.5 \\
\hline 24 & 140 & 120 & 5 & 67.16 & 0.29 & 0.037 & 2 \\
\hline 24 & 140 & 160 & 5 & 59.54 & 0.25 & 0 & 2 \\
\hline 28 & 120 & 80 & 3 & 157.18 & 0.25 & 0.01 & 2.5 \\
\hline 28 & 120 & 120 & 3 & 125.17 & 0.35 & 0 & 2 \\
\hline 28 & 120 & 160 & 3 & 104.03 & 0.34 & 0 & 2 \\
\hline 28 & 120 & 80 & 4 & 111.63 & 0.3 & 0 & 2 \\
\hline 28 & 120 & 120 & 4 & 74.91 & 0.3 & 0.025 & 2 \\
\hline 28 & 120 & 160 & 4 & 66.89 & 0.23 & 0.007 & 2 \\
\hline 28 & 120 & 80 & 5 & 120.28 & 0.29 & 0.005 & 2 \\
\hline 28 & 120 & 120 & 5 & 76.95 & 0.25 & 0.057 & 2.5 \\
\hline
\end{tabular}


Table 1. Estimated parameters of complete model for all experiments (average of replicates) - Continued

\begin{tabular}{cccccccc}
\hline $\begin{array}{l}\text { Moisture content } \\
(\%, \mathrm{wb})\end{array}$ & $\begin{array}{l}\text { Temperature } \\
\left({ }^{\circ} \mathrm{C}\right)\end{array}$ & $\begin{array}{l}\text { Screw speed } \\
(\mathrm{rpm})\end{array}$ & $\begin{array}{l}\text { Nozzle } \\
\text { diameter }(\mathrm{mm})\end{array}$ & $\begin{array}{l}\text { Mean residence } \\
\text { time, } t(\mathrm{~s})\end{array}$ & $\begin{array}{l}\text { Plug flow } \\
\text { fraction, } p\end{array}$ & $\begin{array}{l}\text { Dead volume } \\
\text { fraction, } d\end{array}$ & $\begin{array}{l}\text { Number of } \\
\text { CSTRs, } n\end{array}$ \\
\hline 28 & 120 & 160 & 5 & 48.15 & 0.26 & 0.029 & 2.5 \\
28 & 140 & 80 & 3 & 116.86 & 0.28 & 0.016 & 2 \\
28 & 140 & 120 & 3 & 71.05 & 0.28 & 0.023 & 2.5 \\
28 & 140 & 160 & 3 & 69.35 & 0.22 & 0 & 2 \\
28 & 140 & 80 & 4 & 109.15 & 0.27 & 0 & 2 \\
28 & 140 & 120 & 4 & 86.71 & 0.28 & 0.016 & 2.5 \\
28 & 140 & 160 & 4 & 61.26 & 0.24 & 0.038 & 2.5 \\
28 & 140 & 80 & 5 & 110.51 & 0.29 & 0 & 2.5 \\
28 & 140 & 120 & 5 & 74.25 & 0.27 & 0 & 2.5 \\
28 & 140 & 160 & 5 & 81.68 & 0.36 & 0.04 & 2 \\
\hline
\end{tabular}

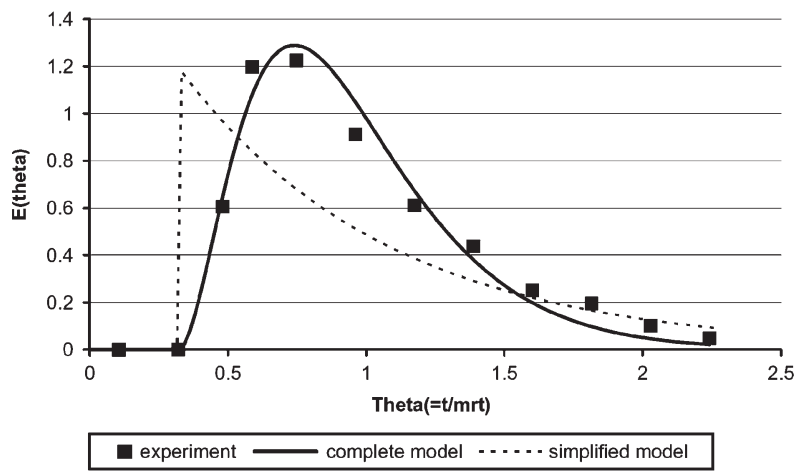

Figure 3. Predicted residence time distribution (RTD) by complete model and simplified model with respect to the experimental RTD.

processing material. The $\bar{t}$ changed with all variables; screw speed, moisture content, nozzle diameter and barrel temperature. It varied from 37-157 s over the range of input variables considered. There was 3-way interaction involved between moisture content, barrel temperature and screw speed $(p<0.01)$. As expected, when other variables were kept constant, $\bar{t}$ increased with decreases in screw speed. $\bar{t}$ also increased with increases in moisture content. There were no interactions of screw speed with nozzle diameter. When die nozzle diameter was increased from 3 to $4 \mathrm{~mm}, \bar{t}$ decreased by $24 \mathrm{~s}$ but there was no change in $\bar{t}$ between die nozzle diameters of 4 and $5 \mathrm{~mm}$. Similar results were reported by Altomare and Ghossi (1986) and Ruyck (1997) and Yeh, Hwang, and Guo (1992). According to Ruyck (1997), die pressure increased with decreasing die diameter due to greater degree of fill and die pressure affected RTD only for die diameter below $4 \mathrm{~mm}$. However, Ziegler and Aguilar (2003) reported the effect of feed rate was more pronounced than screw speed when screw configuration was devoid of conveying elements. Herein, the feed rate varied in proportion to screw speed and, hence, was not considered as an independent variable.

The value of $p$ accounts for the part of the conveying zone inside the extruder. In the case of plug flow only (only conveying) the value of $p$ is one, whereas in case of CSTRs only (screw elements with high mixing element) the value of $p$ is 0 . In our experiments, the value of $p$ ranged from 0.13 to 0.44 . This implies that the Wolf-
Resnich model (with $p$ equal to zero) was not suitable for these extrusion conditions. All variables (screw speed, moisture content, nozzle diameter and barrel temperature) had significant effects on the fraction of plug flow, $p$. There was a 3-way interaction between moisture content, screw speed and nozzle diameter. Also, the 2-way interactions between moisture content with temperature and moisture content with screw speed were significant. In general, with an increase in screw speed, the value of $p$ decreased indicating that the increase in screw speed may have started melting of starch earlier due to more viscous heat generation and so the conveying zone was reduced. For estimation, the regression quadratic model had a low $r^{2}$ value, but the RMSE also was very low.

The value of $d$ is indicative of the fraction of dead volume, which elongates the tail in the distribution. There were no 4-way or 3-way interactions between the input variables. Only moisture content and barrel temperature were found to be confounding. However, there was no significant difference between 120 and $140{ }^{\circ} \mathrm{C}$ barrel temperatures at any moisture content except for $16 \%$, for which the $d$ value decreased from 0.11 to 0.03 as the barrel temperature increased. This may be attributed to increased fluidity of the starch material at $16 \%$ $\mathrm{mc}(\mathrm{wb})$ when the temperature was raised from 120 to $140{ }^{\circ} \mathrm{C}$. With change in nozzle diameter, the value was highest at $4 \mathrm{~mm}$ and lowest at $3 \mathrm{~mm}$. Screw speed had no significant affect on the $d$ value. However, the change in $d$ value was low within the range of input variables. The reason for the small range in $d$ values (0-0.161) may have been, as found by Yeh and Jaw (1999), that the $d$ value was influenced primarily by screw configuration and during this investigations, the screw configuration was kept constant. The other reason may be that for all the runs, the feed rate was maintained at a maximum level that corresponded to the screw speed resulting in similar dead volume fractions.

The $n$ value describes the degree of mixing. An optimum value of $n$ is low in the case of high degree of mixing and vice-versa. It was affected significantly by the screw speed, nozzle diameter and moisture content but not by barrel temperatures $(p>0.1)$. There were no 4-way or 3-way interactions involved. However, effects 
Table 2. Prediction of complete model parameters from input conditions

\begin{tabular}{|c|c|c|}
\hline Parameters of the model & Statistical method [Regression quadratic equation, $r^{2}$ and RMSE] & Neural network method $\left[r^{2}, \mathrm{RMSE}\right]$ \\
\hline
\end{tabular}

$\mathrm{mc}=$ moisture content; $\mathrm{nd}=$ nozzle diameter; temp $=$ temperature and $\mathrm{ss}=$ screw speed .

of screw speed and nozzle diameter were confounding. Screw speed and nozzle diameters together influenced the $n$ value. The only exception was at $80 \mathrm{rpm}$, where there were no differences in the $n$ values with changes in nozzle diameter. This suggested that both variables controlled the back pressure developed within the extruder and, thereby, influenced the degree of mixing. With increase in moisture content, the decrease in the value of $n$ clearly indicated that an increase in moisture caused a significant increase in the degree of mixing. However, since only conveying screw elements were used, the overall effect on the degree of mixing was minimal. For most conditions, the estimated optimum values were either 2 or 3 (when restricting the value to integers).

\subsubsection{Prediction of the parameters}

It may be inferred from the estimation and analyses of parameters that only $\bar{t}$ and $p$ values were affected significantly within the ranges of the input variables. The parameter $d$ can be taken as a constant for the specific screw configuration used except at low moisture content where the $d$ value depends on the barrel temperature. $n$ can be taken as either 2 or 3 depending on screw speed, moisture content and nozzle diameter.

Statistical quadratic models and NN models were developed to predict $\bar{t}$ and $p$ based on the analysis. Regression equations, along with RMSE and $r^{2}$ for statistical and NN models are shown in Table 2. High $r^{2}$ and low RMSE values show that the quadratic model was better than the NN method (three layer, fully connected back propagation network) for the prediction.

The predicted RTD had high coefficients of determination $\left(r^{2}>0.85\right)$. However, due to the experimental errors (even in replicates of the experimental RTDs), the coefficients of determination were not very high at all conditions.

\section{Conclusions}

Residence time distribution in extrusion can be modeled assuming plug flow in series with a finite number $(n)$ of continuously stirred tank reactors (CSTRs) with dead volume fractions $(d)$. As compared to previously proposed simplified model with one CSTR, the complete model with 2 or 3 CSTRs was best-fit and represented the experimental residence time distribution well. Value of $d$ can be assumed constant for a specific screw configuration. All variables had significant effects on the other two parameters of the model, mean residence time and fraction of plug flow, $p$. For prediction of these two parameters from input variables, statistical quadratic models performed better than a neural network model (with three layers, fully connected back propagation).

\section{Acknowledgments}

The authors acknowledge Robert Weber, Sitaramraju Palwai, and Nathan Wiese for their help in conducting the experiments. The research was done, in part, with funds from the University of Nebraska Agricultural Research Division.

\section{References}

Abdelrahim et al., $1993 \rightarrow$ K. A. Abdelrahim, H. S. Ramaswamy, M. Marcotte and C. Toupin, Mathematical characterization of residence time distribution curves of carrot cubes in pilot scale asceptic processing system, Lebensmittel-Wissenschaft und-Technologie-Food Science and Technology 26 (1993), pp. 498-504.

Altomare and Ghossi, 1986 R. E. Altomare and P. Ghossi, An analysis of residence time distribution patterns in a twin-screw cooking extruder, Biotechnology Progress 2 (1986), pp. 157-163.

Bharath and Dorsen, $1994-$ R. Bharath and J. Dorsen, Neural network computing, McGraw-Hill, New York (1994).

Bigg and Middleman, 1974 D. Bigg and S. Middleman, Mixing in screw extruder. A model for residence time distribution and strain, Industrial and Engineering Chemistry Fundamentals 13 (1974), pp. 66-71.

Chuang and Yeh, 2004 G. C. Chuang and A. I. Yeh, Effect of screw profile on residence time distribution and starch gelatinization of rice flour during single screw extrusion cooking, Journal of Food Engineering 63 (2004), pp. 21-31.

Davidson et al., 1983 V V. J. Davidson, D. Paton, L. L. Diosady and W. A. Spratt, Residence time distribution for wheat starch in a single screw extruder, Journal of Food Science 48 (1983), pp. 1157-1161.

Ganjyal and Hanna, 2002 - G. M. Ganjyal and M. A. Hanna, A review of residence time distribution (RTD) in food extruders and study on the potential of neural networks in rtd modeling, Journal of Food Science 67 (6) (2002), pp. 1996-2002.

Ganjyal et al., 2003 - G. M. Ganjyal, M. A. Hanna and D. D. Jones, Modeling selected properties of extruded waxy maize cross-linked starches with neural networks, Journal of Food Science 68 (4) (2003), pp. 1384-1388. 
Gogoi and Yam, 1994 B. K. Gogoi and L. K. Yam, Relationship between residence time and process variables in a corotating twin-screw extruder, Journal of Food Engineering 21 (1994), pp. 177-196.

Jager et al., 1991 - T. Jager, D. J. Van Zuilichem and W. Stolp, Residence time distribution: mass flow, and mixing in a corotating, twin-screw extruder, Food extrusion science and technology, Marcel Dekker Inc, New York, NY (1991), pp. 71-87.

Kumar et al., 2006 A. Kumar, G. M. Ganjyal, D. D. Jones and M. A. Hanna, Digital image processing for measurement of residence time distribution in a laboratory extruder, Journal of Food Engineering 75 (2) (2006), pp. 237-244.

Levenspiel, $1972 \rightarrow O$. Levenspiel, Chemical reaction engineering, John Wiley \& Sons, New York (1972).

Levich et al., $1967-$ V. G. Levich, V. S. Markin and Y. A. Chismadzhev, On hydrodynamic mixing in a model of a porous medium with stagnant zones, Chemical Engineering Science 22 (1967), pp. 1357-1367.

Ruyck, 1997 H. D. Ruyck, Modeling of the residence time distribution in a twin-screw extruder, Journal of Food Engineering 32 (1997), pp. 75-390.
Wolf and Resnick, $1963 \rightarrow$ D. Wolf and W. Resnick, Residence time distribution in real systems, Industrial and Engineering Chemistry Fundamentals 2 (4) (1963), pp. 287-293.

Wolf and White, $1976>$ D. Wolf and D. H. White, Experimental study of the residence time distribution in plasticating screw extruders, American Institute of Chemical Engineers Journal 22 (1) (1976), pp. 122-132.

Yeh et al., 1992 A. I. Yeh, S. J. Hwang and J. J. Guo, Effects of screw speed and feed rate on residence time distribution and axial mixing of wheat flour in a twin-screw extruder, Journal of Food Engineering 17 (1992), pp. 1-13.

Yeh and Jaw, 1999 A. I. Yeh and Y. M. Jaw, Predicting residence time distribution in a single screw extruder from operating conditions, Journal of Food Engineering 39 (1999), pp. 81-89.

Ziegler and Aguilar, 2003 - G. R. Ziegler and C. A. Aguilar, Residence time distribution in a co-rotating continuous mixer by the step change method, Journal of Food Engineering 59 (2003), pp. 161-167. 